\title{
Antropologia social na versão de Evans-Pritchard - notas em torno dos textos aqui traduzidos
}

\author{
BEATRIZ PERRONE MOISÉS iD \\ Universidade de São Paulo | São Paulo, SP, Brasil \\ perrone@usp.br
}

DOI 10.11606/issn.2316-9133.v30i2pe191850

E. E. Evans-Pritchard pode ser dito o mais "clássico" dos antropólogos. Atesta-o sua presença obrigatória em currículos de formação acadêmica na disciplina, em todos os níveis. Parece ser a única unanimidade, por sinal, numa disciplina consagrada à diversidade humana e (certamente por isso mesmo) tão internamente diversa e divergente em suas propostas e tendências. Mas é também mal conhecido. ${ }^{1}$ Cientistas sociais em formação terão certamente ouvido falar do autor de obras-primas indiscutíveis como Os Nuer Feitiçaria, oráculos e magia entre os Azande, e terão lido trechos dessas monografias exemplares. Dificilmente terão ouvido falar das ideias que o distinguem na reflexão antropológica, de modo geral eclipsadas por classificações como "escola britânica" ou "estrutural-funcionalismo". Os três textos aqui reunidos convidam a reconhecer um célebre desconhecido. ${ }^{2}$

Começamos por duas conferências de Evans-Pritchard, apresentadas e publicadas em contextos acadêmicos ${ }^{3}$, que expressam claramente o que ele propunha para a disciplina que chamava de antropologia social. Nelas, o autor retoma trajetos históricos da reflexão antropológica, situa claramente suas heranças intelectuais, apresenta suas reflexões críticas a respeito de outras propostas e expõe suas convicções.

\footnotetext{
${ }^{1}$ Pode parecer contraditório, mas a bem observar, é isso mesmo que costuma ocorrer: é como se a celebridade de um/a autor/a aumentasse na medida inversa de sua efetiva compreensão; quanto mais famosos, autores e teorias, e quanto mais forem generalizadas pelo uso suas ideias, mais serão empobrecidas, enrijecidas, transformadas em outras, até invertidas - como Dumont mostra em relação a Evans-Pritchard. Razão a mais para sempre reler os clássicos.

${ }^{2}$ Os três textos aqui reunidos foram traduzidos por mim no contexto da disciplina "Teorias Antropológicas Clássicas”, sob minha responsabilidade, no PPGAS-USP, em 2021. Muitas das observações registradas nesta apresentação foram desenvovidas no contexto do diálogo com alunas e alunos dessa disciplina, a quem agradeço. Este conjunto foi inicialmente pensado como material didático, e foi revisto desde então

3 "Social Anthropology: Past and Present". The Marett Lecture, 1950. Man, Vol. 50 (1950), pp. 118-124; e "The comparative method in social anthropology", publicada em Evans-Pritchard, E. E. The position of women in primitive societies and other essays in social anthropology. London 1965, Cap. 1, pp. 13-36. Em linhas gerais, os argumentos expostos nas conferências (mais na primeira) também estão presentes numa série de conferências feitas por Evans-Pritchard para a BBC, voltadas para a divulgação, reunidas sob o título de Social Anthropology e publicadas em 1951. Ver bibliografia ao fim.
} 
A primeira dessas conferências, "Antropologia social: passado e presente”, é sempre mencionada em apreciações da contribuição de Evans-Pritchard: conhecida como sua “Marett Lecture de 1950", expressa o rompimento em relação à antropologia social na versão de Radcliffe-Brown. É de método que se trata, como o autor deixa claro já no primeiro parágrafo. É nessa conferência que, como diz Louis Dumont (no terceiro texto incluído nesta coleção $)^{4}$, Evans-Pritchard “detona a bomba” que já estaria armada desde Os Nuer. Para além das passagens de Os Nuer lembradas por Dumont, tudo nas monografias de Evans-Pritchard com efeito distancia sua antropologia social da ciência natural da sociedade proposta por seu professor e antecessor. Dumont mostra também que os desenvolvimentos impulsionados pelas obras de Evans-Pritchard caminharam de modo geral no sentido contrário daquilo que tais obras propunham. Sob o efeito aparentemente inescapável da teoria dominante, reflexões que supostamente levavam adiante propostas de Evans-Pritchard, observa Dumot, operam com reificação de grupos e de recortes conceituais, quando o que uma obra como $O s$ Nuer apresentava era o oposto: relações e sistemas de relações.

A segunda conferência foi proferida na London School of Economics and Political Sciences, em 1963. Nela, Evans-Pritchard revisita tudo o que fora proposto na antropologia social com o nome de método comparativo. Seu título é "O método comparativo em antropologia social”. Note-se que esse é exatamente o título de uma famosa conferência de Radcliffe-Brown feita 12 anos antes, e que aqui explicitação do afastamento em relação às propostas deste é feita de modo ainda mais contundente, no bojo de uma crítica certeira e implacável a todas as formas de comparação propostas na disciplina. Começa afirmando temer "não poder dizer nada de novo", tendo em vista o volume de escritos e propostas de utilização de métodos comparativos na antropologia, que finalmente corresponde a toda a literatura antropológica - "já que não há outro método”, diz. Sua exposição é outra aula de crítica metodológica. Autores do século XIX, tanto quanto Radcliffe-Brown, teriam afinal aplicado um método que antes deveria ser chamado de "por ilustração": com um modelo teórico em mente, basta selecionar alguns exemplos etnográficos a que o tal modelo poderia ser aplicado:

[as] generalizações, fundadas numas poucas ilustrações selecionadas, ou são gerais a ponto de não significarem nada ou, quando formuladas com maior precisão, assentam-se sobre uma base muito tênue de evidências e não levam em conta as evidências contrárias.

A história da antropologia retraçada por Evans-Pritchard nessas conferências localiza no iluminismo o surgimento de ideias que permaneceriam imperando na futura disciplina acadêmica: propunha-se o estudo comparado de sociedades, consideradas como "sistemas naturais ou organismos", que só podiam ser estudadas por observação direta

\footnotetext{
${ }^{4}$ Prefácio de L. Dumont à edição francesa de Os Nuer, in Evans-Pritchard, Les Nuer. Description des modes de vie de des institutions politiques d'un peuple nilote. Paris, Gallimard, 1968, pp. i-xviii.
} 
(método empírico-indutivo) e que, como outras ciências naturais, descobriria leis, decorrentes de uma natureza humana igual em todas as sociedades e todos os tempos. Já de saída é possível ver uma tendência forte e persistente que a apresentação de Evans-Pritchard ressalta: na prática, fala-se muito em ciência empírica, mas as ideias não decorrem do estudo de casos concretos; casos concretos são selecionados para ilustrar teorias pensadas em sua ausência. E isso vai do século XVIII ao XX, como nota nosso professor. ${ }^{5}$ Os pioneiros de outra ideia fundamental na configuração da disciplina, a de que sociedades primitivas podiam "merecer a atenção de especialistas sérios", foram McLennan, Tylor e Morgan, diz ele. Os pontos fundamentais da antropologia social à lá Evans-Pritchard já estão aí destacados: defesa constante do estudo empírico de casos concretos e "primitivos" merecedores de respeito intelectual. Elegante, mesmo quando discorda, nosso autor demonstra também respeito para com colegas e antecessores: gente capaz, com perguntas pertinentes e interessantes propostas de resposta, que terá no mínimo demonstrado a não-pertinência ou o desinteresse de métodos e ideias recorrentes, e contribuído para assegurar o registro de muitos "casos concretos".

Tanto o valor como as fraquezas do método comparativo [...] estão patentes no trabalho pioneiro de McLennan - pontua EvansPritchard. Seu valor está sobretudo em ter permitido que ele extraísse o geral do particular e, ao fazê-lo, que nos desse conceitos classificatórios importantes no desenvolvimento da antropologia social.

Vale a pena notar que Evans-Pritchard conta uma história da reflexão antropológica que não parte de classificações gerais ("escolas", "paradigmas"), ilustradas por autores específicos, mas ao contrário: é da consideração de autores específicos - "casos concretos", no plano das teorias. Aqui os casos principais são McLennan e Tylor, de cuja obra EvansPritchard extrai o "geral" de uma geração e uma fase da teoria antropológica, o que se poderia chamar de "evolucionismo".

Evans-Pritchard conta em suas conferências uma história do pensamento antropológico que começa com iluministas franceses e escoceses, expressa entrelaçamentos e influências mútuas com a escola sociológica francesa, comenta e discute contemporâneos ingleses e norte-americanos à luz de heranças persistentes, a que se vai contrapondo conforme apresenta. "Ele tinha uma visão muito precisa e muito refletida sobre o desenvolvimento da antropologia social”, observaria André Singer ${ }^{6}$ ao introduzir uma

\footnotetext{
${ }^{5}$ Dumont lembra que essas conferências, em suas versões acadêmicas ou de divulgação, correspondiam fundamentalmente ao conteúdo das aulas de Evans-Pritchard.

${ }^{6}$ A history of anthropological thought, organizado por André Singer com Prefácio de Ernest Gellner (1981). Como informa Singer nesse mesmo prefácio, Evans-Pritchard trabalhava nesse livro, que reuniria reflexões dispersas em outras publicações (como as conferências), quando faleceu. A seleção dos textos, ressalta também o organizador, não é de Evans-Pritchard, e vários capítulos que ele deixou em estado de notas talvez substituíssem alguns dos mais acabados, publicados nessa coletânea. O primeiro capítulo é dedicado a
} 
coletânea póstuma de escritos de seu professor que expressava essa visão, agora na forma de capítulos dedicados a autores.

O "Prefácio" de Louis Dumont à edição francesa de Os Nuer ressalta diversos pontos da proposta de Evans-Pritchard na Marett Lecture, situa o autor e a obra na antropologia inglesa (acompanhando David Pocock na maior parte desse trajeto), aproxima-o de Mauss e Lévi-Strauss, critica a "antropologia política" e os desvios no parentesco que resultaram, finalmente, da prevalência de modelos teóricos a que nosso autor se contrapunha. Como Evans-Pritchard, Dumont é um antropólogo que escapa de classificações nacionais e/ou teóricas. Se ele mesmo insiste em distinguir antropologias por nacionalidade nessa introdução (como aliás faz também Evans-Pritchard), faz notar que antropólogos são pessoas de suas culturas, cujos pensamentos fazem sentido em contextos intelectuais particulares. Ele mesmo é francês, aliás, quando aproxima Evans-Pritchard e Lévi-Strauss a partir de uma concepção de "estruturalismo" que dominava naquele seu contexto intelectual. Dumont diz, por exemplo, que Evans-Pritchard teria "descoberto" o estruturalismo, ao passar de oposições "de fato" para oposições “conceituais". Reitera aí uma leitura tão corrente quanto enganosa do que seria "estruturalismo", que o entende como entrincheirado no plano de "conceitos" e "linguagens". Ora, tanto no "estruturalismo" de Lévi-Strauss como no de Evans-Pritchard, oposições "de fato" e oposições "conceituais" são indissociáveis, em qualquer plano considerado. As "estruturas", por sua vez, não são nem mais nem menos "sociológicas" do que "simbólicas" - ambos autores operam com a ideia de que formas de organização social só são compreensíveis no contexto em que se inserem, de que estão, em cada caso considerado, conectadas por transformação a sistemas de pensamento, práticas e modos de vida, sempre particulares. ${ }^{7}$

Dumont fala do "método" que teria sido aplicado por Evans-Pritchard em Os Nuer, fundado num princípio da "relatividade da linguagem". Segundo esse preceito, o significado de palavras/conceitos varia de acordo com o contexto, e nisso Evans-Pritchard se aproximaria de Lévi-Strauss, ou do "estruturalismo" que Dumont tem em mente. Cabe notar que são os Nuer que aplicam o princípio, conforme nos explica Evans-Pritchard. Assim como "sistema segmentar" é o nome que ele dá para as linhas mestras do modo de organização dos Nuer, não uma ferramenta analítica aplicada ao caso concreto - assim operariam os praticantes de métodos "ilustrativos". Aqui também Dumont parece preso a uma dificuldade geral de reconhecer o estatuto da teoria nativa no "modelo abstrato" que Evans-Pritchard apresenta. A reflexão de Dumont é pontuada por frases como "grupos nomeados pelos Nuer, ainda que estruturais”, e ele afirma que foi Evans-Pritchard que “optou por ressaltar o caráter territorial [dos grupos]". Ora, os grupos em questão são

\footnotetext{
Montesquieu, o que parece bem de acordo com a história que o professor contava, e capítulos inacabados sobre Mauss, Radcliffe-Brown e White, entre outros, seriam sem dúvida muito esclarecedores de uma visão muito precisa, muito bem fundamentada e refletida da antropologia social - e muito original, poderíamos acrescentar. 7 Outra aproximação notável entre Evans-Pritchard e Lévi-Strauss está na ênfase nas diferenças. Na conferência sobre o método comparativo, dirá o primeiro: "Gostaria de enfatizar a importância das diferenças para a antropologia social enquanto disciplina comparativa, pois é possível dizer que no passado a tendência dominante foi de enfatizar as semelhanças”.
} 
"estruturais" na monografia porque o são para os Nuer, que não só os nomeiam como os definem, concebem e operam em termos territoriais. Na antropologia social de EvansPritchard, definitivamente, não é o antropólogo quem decide o que é estrutural ou o que merece ser ressaltado. Evans-Pritchard parece mais revolucionário do que Dumont - e leituras correntes - está preparado para reconhecer.

O texto de Dumont contribui para ressaltar a originalidade de Evans-Pritchard, para demonstrar o quanto os efeitos de suas obras se afastaram dos desafios que suas monografias propunham, e ao mesmo tempo situa o próprio Dumont. Este, tão contundente quanto Evans-Pritchard na conferência de 1963, retoma sua própria reflexão para chamar a atenção para uma antropologia na "poltrona metafísica", que opera com a noção moderna de indivíduo e seus corolários. Mauss já tinha demonstrado o caráter restrito da noção de indivíduo, Dumont nota que povos não-modernos não operam com ela. ${ }^{8} \mathrm{O}$ alerta continua sendo necessário: operando seus próprios conceitos (como o de indivíduo) como se fossem categorias analíticas universais, não é possível entender, menos ainda traduzir, modos de pensamento outros. Retomarei a excelente imagem da "poltrona metafísica", que Dumont compara à poltrona física dos ditos antropólogos de gabinete. Inclusive porque às vezes nem ele mesmo consegue desgrudar dela.

Voltando ao lugar central de teorias nativas. Nesse ponto, que diz respeito ao que se pode chamar de "ciência social do observado", Evans-Pritchard, como Lévi-Strauss, costuma ser lido às avessas: oposições, estruturas, relações por transformação, códigos, não estão "nas mentes" dos autores, no sentido de que seriam "modelos teóricos" de sua lavra, aplicados aos fatos. As tais oposições e suas operações, estruturas e linguagens, tudo emerge, no caso de ambos, daquilo que se propõem a estudar, entender e apresentar. Ambos de fato "descobrem" estruturas, percebidas como sistemas que se transformam entre planos "sociológicos" e "ideológicos", que operam com códigos específicos e variáveis, que se transformam no tempo e no espaço, que perduram na transformação. ${ }^{9}$ Mas não se pode dizer, com Dumont, que descobrem "o estruturalismo".

Nas conferências, lê-se a declaração inequívoca de Evans-Pritchard de sua oposição à concepção da antropologia como ciência em busca de leis, e a apresentação de sua própria visão da disciplina a que dedicou a vida, "sem arrependimentos", como ele mesmo observa. As monografias de Evans-Pritchard, sem o dizerem, realizam a antropologia social na versão descrita por ele como disciplina das humanidades, dedicada à tradução intercultural.

[O que faz um antropólogo? Pergunta Evans-Pritchard. E responde:]

Vai viver por alguns meses ou anos com povos primitivos. Vive tão próximo deles quanto possível, aprende a falar sua língua, a pensar com seus conceitos e a sentir seus valores. Depois revive essas experiências de modo crítico e interpretativo, nas categorias

\footnotetext{
${ }^{8}$ Sahlins (2008) retomaria esse tema, exatamente pela vertente "política" a que Dumont se dedica neste texto.

${ }^{9}$ Considero mais de perto as estruturas em Evans-Pritchard em Perrone-Moisés (2001).
} 
conceituais e valores de sua própria cultura e nos termos do conjunto de conhecimentos de sua disciplina. Em outras palavras, traduz de uma cultura para outra.

O lugar central do pensamento e da palavra nativos decorrem diretamente da proposta de tradução, que reconhece modos de vida humanos como linguagens distintas, só compreensíveis em seus próprios contextos e dinâmicas. Mesmo no plano da abstração, trata-se de tornar sociedades específicas inteligíveis, nunca de propor modelos de aplicação universal. Buscar apresentar formulações e compreensões nativas - um pensamento em seus próprios termos - é de fato o contrário de buscar leis científicas. Mas há mais. A tradução é um dos níveis do trabalho de antropólogos. O outro é o nível da análise sociológica.

Na segunda fase de seu trabalho, o antropólogo social dá um passo além e busca, pela análise, revelar a forma latente subjacente de uma sociedade ou cultura - esclarece na Marett Lecture.

Evans-Pritchard insiste na importância do treinamento de antropólogos-tradutores, que tanto garante a qualidade da tradução como os qualifica para a percepção de "padrões" próprios às culturas traduzidas. Tais padrões não são conscientes nos nativos, e tampouco são visíveis a amadores.

[Como tradução] - prossegue a Marett Lecture - a antropologia social é uma arte literária e impressionista. Mas mesmo num estudo etnográfico específico o antropólogo tenta fazer mais do que compreender o pensamento e os valores de um povo primitivo e traduzi-los para sua própria cultura. Também procura descobrir a ordem estrutural da sociedade, os padrões que, uma vez localizados, lhe permitem vê-la como um todo, como um conjunto de abstrações inter-relacionadas. Assim, a sociedade se torna não somente inteligível tal como é, no nível da consciência e da ação, mas também sociologicamente inteligível.

[...] um antropólogo descobre na sociedade nativa algo que nenhum nativo poderia lhe explicar e que nenhum leigo, por mais que participe daquela cultura, pode perceber - sua estrutura de base. Essa estrutura não pode ser vista. É um conjunto de abstrações e cada uma delas, embora derivadas da análise de comportamento observado, é fundamentalmente uma construção do próprio antropólogo. Relacionando essas abstrações umas às outras logicamente, de modo a apresentarem um padrão, ele pode ver a sociedade naquilo que é essencial e como um todo. 
Há ainda um terceiro nível, em que tais padrões são comparados. Evans-Pritchard fala até em tipologia. Poderia talvez ter desenvolvido uma teoria sobre o "tipo segmentar", que detectou entre os nuer e entre os beduínos da Cirenaica. Mas não parece tê-lo feito como comentei acima, nem sequer menciona aqueles ao falar destes. Muitas das reflexões sobre sua visão da antropologia social nas conferências dão indícios do porquê.

Um ponto importante de nosso professor nas conferências é que e a antropologia e a história só têm a ganhar com uma real aproximação. Insiste em que nada no modo como antropólogos procedem os distingue de historiadores - trata-se de "uma diferença técnica, não metodológica”. Evans-Pritchard faz notar o quanto o apego ao modelo das ciências naturais afastava a antropologia da história: sob roupagem histórica, teorias evolucionistas ilustram ideias próprias com fatos desgarrados, e teorias funcionalistas supõem que a história não precisa ser conhecida, nem levada em conta, para compreender o funcionamento de um sistema social num dado momento do tempo:

é difícil conciliar a afirmação de que uma sociedade veio a ser o que é através de uma sucessão de eventos particulares com a afirmação de que pode ser descrita de modo abrangente em termos de lei natural. Em sua forma extrema, o determinismo funcionalista leva ao relativismo absoluto e não faz sentido, nem para a teoria em si nem para qualquer pensamento. [...] a meu ver, negligenciar a história das instituições impede antropólogos funcionalistas não só de estudar questões diacrônicas como também de testar as próprias construções funcionais que mais valorizam, pois é precisamente a história que lhe fornece uma situação experimental - afirma na Marett Lecture. ${ }^{10}$

Evans-Pritchard evoca diversos historiadores, e qualifica sua própria monografia, Os Sanusi da Cirenaica (1949), como um livro de história, cuja narrativa é "essencialmente igual à da história social”. Essa obra, em geral esquecida e pouco lida, merece alguns comentários. Como mais tarde faria Sahlins em "Ilhas de História”, Evans-Pritchard narra e explica fatos históricos a partir do entrelaçamento de modos locais de organização e pensamento, eventos, e ação de determinados indivíduos. A história não tem leis, tampouco as sociedades, mas as "leis" de cada forma particular de organização social e pensamento explicam o desenvolvimento particular de cada história. Compreender a história particular de uma ordem islâmica que se tornou um "proto-Estado" num contexto de guerras coloniais depende de conhecer a Cirenaica onde a ordem se desenvolveu, o sistema segmentar que é o dos beduínos, o modo como o fundador, o Grande Sanusi, encaixou os "centros" da ordem missionária nesse sistema pré-existente, os projetos coloniais europeus, os não-

${ }^{10}$ Tanto o que Evans-Pritchard aqui diz é verdade, que num texto como "O irmão da mãe na África do Sul", Radcliffe-Brown reforça sua hipótese reconhecendo sua operação em transformação, da Inglaterra feudal à Inglaterra moderna. Mas a antropologia social que se fortalecia em torno de Evans-Pritchard sentia-se de fato apartada da história. 
entendimentos e embates entre personagens $\operatorname{coletivos}^{11}$, as estratégias de personagens individuais. Evans-Pritchard expõe "estruturas da conjuntura" com a mesma riqueza que Sahlins. Mas não dá nomes ao que faz.

De fato, nas monografias de Evans-Pritchard, debates teóricos especializados têm pouco espaço. Ao falar da tomada de posição na Marett Lecture como a explosão de uma "bomba" já armada, Dumont fala de "tática". Mas a prática de apresentar, limitando-se a apontar alguns debates e comparações possíveis aqui e ali parece ser antes o estilo de EvansPritchard em suas celebradas monografias. Estas são de fato traduções "dos termos de uma cultura nos termos de outra”, não evocam debates de especialistas (que só elas podem alimentar) nem conjuntos eruditos de referências bibliográficas. Note-se nesse sentido que, em Os Sanusi da Cirenaica, nosso autor nos apresenta em operação, entre os beduínos do norte da atual Líbia, um sistema segmentar em tudo análogo ao dos Nuer. E embora em certa passagem fale de "sistema segmentar clássico", não discorre sobre o tal sistema, não tira da recorrência qualquer proposta tipológica, e nem sequer cita seus próprios escritos anteriores. As traduções feitas por Evans-Pritchard de modos de vida/pensamento de povos nãoeuropeus apresentaram a todas as disciplinas das humanidades desafios de monta: outras racionalidades, outras políticas, outras religiões, a centralidade das relações entre grupos humanos e seu meio, modos variados de compor grupos, história e estrutura, relações (de transformação) entre modos de organização social, pensamentos, modos de vida, inclinações, conceitos, sentimentos. Ao fazê-lo, opera com clareza quanto aos cortes que faz nas redes sempre complexas das coisas, elegendo perguntas norteadoras e com elas as informações de que seus leitores precisam para acompanhar a construção das respostas. Ao mesmo tempo, reafirma constantemente o não-sentido do que quer que seja fora de seu contexto, e o caráter múltiplo do "contexto".

Dumont fala na "escola" de Evans-Pritchard, muito embora ressalte as distâncias entre ele e seus contemporâneos e sucessores, e sua posição sui generis. Evans-Pritchard realmente não parece ter feito escola e permanece desafiador. Até para Dumont, em cujo texto permanece forte a tendência da poltrona metafísica da noção de grande autor individual, produtor original de teorias próprias. Como se Evans-Pritchard fizesse precisamente o que critica: "construções postuladas e impostas aos fatos". Dumont fala de uma ambiguidade em Os Nuer quanto ao tratamento de relações de parentesco, entre sistema de parentesco e conjunto de relações de parentesco individuais, e novamente parece confundir suas próprias noções de estrutura e sistema com o que Evans-Pritchard descreve entre os Nuer - arriscaria dizer, finalmente, que não há ambiguidade: ocorre que a filosofia não-substancialista que subjaz ao modo de organização desse povo nilótico (e de tantos outros) pode simplesmente não ser percebida por leitores ocidentais.

O que Dumont apresenta na conclusão de seu prefácio como "teorias de EvansPritchard”, "conquista pessoal própria do autor” (!), são abstrações de teorias dos povos nãoocidentais da África que Evans-Pritchard tão bem traduziu. "Sistema segmentar", por

\footnotetext{
${ }^{11}$ Dignas de nota são suas análises dos afastamentos e incompreensões mútuas entre italianos e ingleses em luta pelo domínio da Cirenaica.
} 
exemplo, não é uma ferramenta analítica: é o nome que nosso autor dá àquilo que vê operar entre os Nuer e, mais tarde, também entre os beduínos da Cirenaica - com variações, evidentemente.

No tom sutil e modesto que o caracteriza, o próprio Evans-Pritchard enfatiza, no final de sua conferência sobre o método comparativo, a prioridade das traduções monográficas sobre os construtos teóricos, em sua visão da antropologia social:

Talvez eu devesse me considerar primeiro como etnógrafo, e em segundo antropólogo social, pois acredito que um entendimento adequado dos fatos etnográficos deve vir antes de qualquer análise realmente científica.

Digno de nota que nessa passagem ele reaproxime a antropologia etnográfica que professa das ciências naturais, mas agora as experimentais. Que não permitem a formulação de leis. "Lidamos com sentimentos, propósitos, vontade, razão, escolha, e, também, circunstâncias históricas", lembra nosso autor. O que continua a desafiar nossa imaginação na obra de Evans-Pritchard são modos de ser, de crer, de se organizar, de povos da África. Em suas excelentes traduções (comentadas) das teorias desses povos para os ocidentais modernos, categorias e encadeamentos nativos são aquilo que se trata de descrever e tornar compreensível. Era isso que Evans-Pritchard propunha e foi isso que fez, desde a primeira monografia dedicada aos Azande, com maestria. Já a ideia de que é o pensamento de outros - "entendimento adequado dos fatos etnográficos" - que tem prioridade, essa talvez pudesse ser atribuída ao gênio individual de Evans-Pritchard, se não fosse pela companhia de pelo menos outro gênio individual, Lévi-Strauss, no projeto de chegar às ciências - não apenas sociais - dos "observados", no propósito de apresentar modos de vida e de pensamento próprios de povos não-ocidentais modernos. ${ }^{12}$

Dumont afirma que

para julgar o valor definitivo de uma determinada orientação em antropologia social, podemos nos perguntar em que medida ela de fato trabalha para unificar as salientes diferenças entre sociedades "primitivas" e aquelas mais complexas que podem ser chamadas de "tradicionais", de um lado, e do outro o tipo moderno de sociedade.

O horizonte da afirmação é o universal, uma das sustentações da "poltrona metafísica" ocidental. ${ }^{13}$ A afirmação de Dumont é a de um francês moderno, que combate

\footnotetext{
${ }^{12}$ As profundas afinidades entre esses dois grandes mestres da antropologia, que de modo pioneiro e genial levaram a sério os "nativos" de que se faziam tradutores, merecem atenção mais detida. Não cabe evidentemente desenvolvê-las aqui.

${ }^{13}$ A trilogia ordenada por complexidade, que comparece nas mais variadas obras de antropologia, com ou sem debates, faz dessa ideia um campo de reflexão em si. Evans-Pritchard também opera com distinções entre "primitivos" e "civilizados", indaga se "faz sentido" classificar juntos os índios da Califórnia, "culturalmente
} 
preconceitos e anseia pela igualdade - vamos abolir as diferenças! Persistem as origens iluministas, onde Evans-Pritchard localiza conceitos e preceitos insistentes na disciplina, que impedem de realizar o projeto de conhecimento que é o seu. O que interessa, para avaliar antropólogos como Evans-Pritchard, é dar-se conta de que respeito pela diferença é o contrário de sua erradicação. ${ }^{14}$

\section{Referências bibliográficas}

EVANS-PRITCHARD, E. E. 1937. Witchcraft, oracles and magic among the Azande. Oxford, Oxford Univ. Press.

EVANS-PRITCHARD, E. E. 1940. The Nuer. A Description of the Modes of Livelihood and Political Institutions of a Nilotic People. Oxford, Clarendon Press

EVANS-PRITCHARD, E. E. 1949. The Sanusi of Cyrenaica. Oxford, Clarendon Press. EVANS-PRITCHARD, E. E. 2021 [1950]. "Antropologia Social, passado e presente". Cadernos de Campo, vol. 30, n. 2: e191852. DOI 10.11606/issn.23169133.v30i2pe191852

EVANS-PRITCHARD, E. E. 1951. Social Anthropology (BBC conferences). Londres, Cohen \& West.

EVANS-PRITCHARD, E. E. 1981. A history of anthropological thought. Nova Iorque, Basic Books.

PERRONE-MOISÉS, Beatriz. 2001. “Conflitos recentes, estruturas persistentes: notícias do Sudão”. Revista de Antropologia, n. 44: 127-145. DOI 10.1590/S003477012001000200004

RADCLIFFE-BROWN, Alfred Reginald. 1973 [1924]. “O irmão da mãe na África do Sul”. In: Estrutura e Função na Sociedade Primitiva. Petrópolis: Vozes, pp. 27-45.

SAHLINS, Marshall. 1985. Islands of History. University of Chicago Press

\footnotetext{
desenvolvidos", e os aborígenes australianos, fala em "bárbaros" ... Nenhum sinal de critério de superioridade, nenhum sinal de pretensão ocidental ao "topo" de qualidade. Mas os distintivos permanecem. O que coloca um outro problema: o que pode querer dizer "bárbaro" em Evans-Pritchard, que emprega a palavra para falar, por exemplo, dos beduínos da Cirenaica, pelos quais nutre uma sincera e explícita admiração?

${ }^{14}$ Tem sido comum julgar obras como a de Evans-Pritchard a partir de características da pessoa. EvansPritchard era inglês, branco, aristocrata, acadêmico, o que obviamente configura suas ideias, mas não se pode supor de saída o que uma pessoa "dessas" teria pretendido, dito ou escrito. Ainda menos quando a pessoa em questão alerta constantemente para as "condicionantes" europeias que dificultam a compreensão de pensamentos e atos de povos outros. Tampouco basta saber que se converteu ao catolicismo na maturidade e dedicou e estudos do islamismo e de outras religiões grande parte de sua vida, para supor como, "enquanto católico", teria descrito ou julgado outras religiões. E nisso Evans-Pritchard também propõe um desafio metodológico, aliás: afirmava que para estudar crenças, um antropólogo ele mesmo crente estaria mais bem preparado. Estamos longe mesmo da "objetividade científica", longe da imposição dos valores da própria crença (religiosa ou científica) a crenças alheias. E sobre o que se poderia supor ser o pensamento e posicionamento de alguém que como ele prestou serviços a uma administração colonial europeia na África, consideremos sua definição de guerra colonial: "poder europeu tentando privar um povo nativo de sua liberdade e de sua terra" (em Os Sanusi da Cirenaica).
} 
SAHLINS, Marshall. 2008. The Western Illusion of Human Nature. With Reflections on the Long History of Hierarchy, Equality and the Sublimation of Anarchy in the West, and Comparative Notes on Other Conceptions of the Human Condition. Prickly Paradigm Press.

sobre a autora

\section{Beatriz Perrone-Moisés}

É professora associada do Departamento de Antropologia da Universidade de São Paulo.

Contribuição de Autoria: Não se Aplica

Financiamento: A produção deste artigo não contou com financiamento à pesquisa.

Recebido em 05/10/2021

Aceito para publicação em 08/12/2021 